\title{
ASUPAN NATRIUM DAN STATUS GIZI TERHADAP TINGKAT HIPERTENSI PADA PASIEN RAWAT JALAN DI RSUD KOTA MAKASSAR
}

\author{
Hasbullah Darmawan ${ }^{1}$, Abdullah Tamrin ${ }^{2}$, Nadimin $^{2}$ \\ ${ }^{1}$ RSUD Salewangang, Kabupaten Maros \\ ${ }^{2}$ Jurusan Gizi, Politeknik Kesehatan Kemenkes, Makassar \\ Korespondensi, E-Mail : abdullahtamrin@poltekkes-mks.ac.id
}

\begin{abstract}
Hypertension is a big problem, not only in western countries but also in Indonesia. Every year hypertension or high blood pressure contributes to the deaths of nearly 9.4 million people due to heart disease and stroke and if combined these two diseases are the number one cause of death in the world. This study aims to analyze the relationship between sodium intake and nutritional status to the level of hypertension in outpatients in RSUD Makassar City. This study used cross sectional study design. The sample is outpatient of RSUD Makassar City. Data of sodium intake and nutritional status were obtained by recall 1x24 hours and anthropometry measurement, while blood pressure data were obtained from patient rekammedic data. The results showed that samples with normal sodium intake tended to have mild hypertension that was 12 people $(85,7 \%)$ while sample with sodium intake was more likely to have moderate hypertension that is 12 people (75\%). Samples of normal nutritional status with mild hypertension tends to be 12 people (80\%) while the sample with abnormal nutritional status tend to have moderate hypertension is 11 people $(73,3 \%)$. The relationship between sodium intake and nutritional status to hypertension level. It is recommended to hospital nutritionists to provide further consultation on lowsalt diet as well as improved nutritional status. In addition there is also a further understanding of hypertensive patients about the cause of hypertension to be more vigilant against hypertension disease.
\end{abstract}

Keywords: hypertension level, nutritional status, sodium intake

\section{PENDAHULUAN}

Manusia cenderung tidak teratur dalam memperhatikan pola makan seharihari, sehingga akibatnya dapat mengganggu kesehatan. Untuk membuang kebiasaan buruk perlu digantikan dengan melakukan kebiasaan baru yang lebih baik. Secara garis besar Pete Cohen mengatakan bahwa cara menghargai hidup adalah dengan menjalaninya dengan sehat dan teratur seperti minum air putih yang cukup, sarapan pagi setiap hari, dan makan siang yang bergizi tentunya sangat dianjurkan (Anisah dkk, 2011).

Hipertensi merupakan masalah besar, tidak hanya di negara barat tapi juga di Indonesia. Hipertensi diderita oleh satu miliar orang di seluruh dunia dan diperkirakan tahun 2025 melonjak menjadi 1,5 miliar orang. Setiap tahun hipertensi atau tekanan darah tinggi menyumbang kepada kematian hampir 9,4 juta orang akibat penyakit jantung dan stroke dan jika digabungkann kedua penyakit ini 
merupakan penyebab nomor satu di dunia (Ilkafah, 2016).

Prevalensi hipertensi di Indonesia berdasarkan hasil data Riskesdas (Riset Kesehatan Dasar) pada tahun $2013(9,4 \%)$ lebih tinggi dibanding tahun 2007 (7,2\%). Sedangkan prevalensi hipertesi di Sulawesi Selatan tahun 2007 sebesar 5,7\% dan meningkat pada tahun 2013 sebesar 10,3\% (Balitbankes 2007 \& Balitbankes 2013).

Data yang di peroleh dari Rumah Sakit Umum Daerah Daya Kota Makassar pada tahun 2016 jumlah pasien hipertensi rawat jalan, yaitu 1134 pasien yang terhitung mulai dari bulan Januari sampai bulan Desember 2016 (Rekammedik RSUD Daya, 2015).

Bertambahnya jumlah penderita hipertensi berkaitan dengan meningkatnya jumlah penduduk serta adanya perilaku yang tidak sehat seperti perilaku diet yang salah, kurangnya aktivitas fisik, berat badan yang berlebih dan paparan stress persisten. Hipertensi merupakan penyakit yang ada di Sulawesi Selatan. Permasalahan gizi yang dialami orang dewasa cenderung berkaitan dengan kelebihan berat badan (Yulyius, 2014).

Ada beberapa faktor yang menyebabkan seseorang terkena penyakit hipertensi, diantaranya, umur, jenis kelamin dan suku. Selain itu, ada juga faktor genetik dan faktor lingkungan seperti obesitas, stress, konsumsi garam, merokok, konsumsi alkohol dan sebagainya (Anggara, 2013).

Prevalensi status gizi lebih (gemuk) di Sulawesi Selatan yang terendah adalah Tana Toraja $(7,2 \%)$ sedangkan tertinggi adalah Makassar (18,4\%). Tiga kabupaten/kota dengan prevalensi sama atau di atas angka nasional yaitu Pinrang, Makassar, Pare-pare (Balitbangkes, 2013).

Berdasarkan penelitian Rudy Anggara pada tahun 2014 menyatakan bahwa semakin tinggi tingkat obesitas seseorang maka semakin tinggi pula tingkat kejadian hipertensi pada seseorang.
Gaya hidup sesungguhnya merupakan faktor terpenting yang sangat mempengaruhi kehidupan masyarakat. Gaya hidup yang tidak sehat dapat menyebabkan terjadinya penyakit hipertensi, misalnya makanan, aktivitas fisik, stres dan merokok (Pusparani, 2016).

Terjadinya penyakit hipertensi juga erat kaitannya dengan frekuensi makan dan jenis makanan yang dikonsumsi seseorang. Frekuensi makan yang berlebih akan mengakibatkan kegemukan yang menjadi salah satu penyebab terjadinya penyakit hipertensi. Selain itu konsumsi garam juga merupakan pemicu terjadinya penyakit hipertensi (Anisah dkk, 2011).

Hipertensi merupakan masalah kesehatan penting pada pelayanan kesehatan primer karena angka prevalensi yang tinggi dan akibat jangka panjang yang ditimbulkannya. Secara patofisiologi terjadinya hipertensi disebabkan oleh pengaruh hormon diuretik. Natrium diretensi oleh ginjal dan menyebabkan naiknya volume sirkulasi. Peningkatan Natrium dapat pula disebabkan karena diet garam yang tinggi (Mustamin, 2010).

Asupan natrium tinggi dapat menyebabkan peningkatan volume plasma, curah jantung dan tekanan darah. Natrium menyebabkan tubuh menahan air dengan tingkat melebihi ambang batas normal tubuh sehingga dapat meningkatkan volume darah dan tekanan darah tinggi. Asupan natrium tinggi menyebabkan hipertropi sel adiposit akibat proses lipogenik pada jaringan lemak putih, jika berlangsung terus-menerus akan menyebabkan penyempitan saluran pembuluh darah oleh lemak dan berakibat pada peningkatan tekanan darah. Selain hal tersebut, individu berat badan lebih dan obesitas kemungkinan besar memiliki sensitifitas garam yang berpengaruh pada tekanan darah (Kautsar, dkk 2013).

Jumlah penderita hipertensi atau tekanan darah tinggi di Indonesia cukup tinggi. Sehingga akibatnya penyakit ini 
menjadi masalah kesehatan di masyarakat. Hipertensi merupakan salah satu faktor resiko yang paling berpengaruh terhadap kejadian penyakit jantung dan pembuluh darah. Hipertensi umumnya tidak menimbulkan gejala, namun baru disadari setelah menimbulkan gangguan fungsi organ seperti gangguan fungsi jantung atau stroke. Tidak jarang hipertensi ditemukan secara tidak sengaja pada waktu pemeriksaan kesehatan rutin ataupun datang dengan keluhan tertentu.

Selain menyebabkan penyakit kardiovaskuler, hipertensi juga merupakan penyebab terjadinya stroke. Berdasarkan penelitian yang dilakukan Juan dkk (2010) mengatakan seseorang yang mempunyai riwayat hipertensi 2 kali lebih beresiko terkena stroke.

Berdasarkan hal diatas peneliti telah melakukan penelitian tentang hubungan status gizi dan asupan natrium terhadap tekanan darah pada penderita penyakit hipertensi di RSUD Daya Kota Makassar.

\section{METODE}

Jenis penelitian ini merupakan survey analitik observasional dengan menggunakan rancangan penelitian studi potong lintang (cross sectional study). Pengukuran status gizi, asupan natrium dan tekanan darah dilakukan pada satu titik waktu. Serta memperhatikan pola makan pasien selama di rumah.

Pengumpulan data dilakukan di RSUD Kota Makassar yang diperoleh melalui wawancara menggunakan kuesioner berupa identitas sampel, asupan natrium diperoleh melalui recall 24 jam yang ditanyakan langsung kepada responden menggunakan form recall 24 jam, serta status gizi diperoleh melalui pengukuran antropometri dengan mengukur berat badan dan tinggi badan menggunakan timbangan digital dengan ketelitian 0,1 gram dan microtoice dengan ketelitian $0,1 \mathrm{~cm}$ yang kemudian dimasukkan dalam rumus Indeks Massa Tubuh (IMT). Sedangkan data tekanan darah diperoleh dari hasil pengukuran petugas rumah sakit yang diulis dalam buku rekammedik.

Data primer yang didapatkan berupa tinggi badan dan berat badan kemudian dimasukkan dalam rumus IMT (Indeks Massa Tubuh) dan kemudian dihitung untuk mengetahui status gizi dari responden. Sedangkan data asupan natrium yang didapatkan dari hasil recall 24 jam dihitung asupan natrium menggunakan nutrisurvey.

Seluruh data yang didapatkan kemudian di analisis menggunakan SPSS. Hubungan status gizi dengan tekanan darah pada penderita hipertensi di RSUD Daya Kota Makassar dilihat dengan melakukan uji statistic yaitu uji chi square $\left(\mathrm{x}^{2}\right)$ pada tingkat kemaknaan $95 \%$ atau $\alpha=0,05$.

\section{HASIL}

\section{Karakteristik Sampel}

Hasil penelitian menunjukkan bahwa umumnya sampel berjenis kelamin perempuan yaitu sebanyak 18 orang (64,3\%), sebagian besar sampel berusia 40 67 tahun sebanyak 22 orang $(78,6 \%)$, dengan pekerjaan umumnya sebagai IRT sebanyak 10 orang $(35,7 \%)$ dan pendidikan umumnya tamat SMA sebanyak 12 orang $(42,9 \%)$, asupan natrium sampel umumnya lebih yaitu sebanyak 16 orang $(57,1 \%)$, sampel cenderung memiliki status gizi normal yaitu sebanyak 15 orang $(53,4 \%)$ dan jumlah sampel yang mengalami hipertensi ringan dan sedang yaitu sebanyak 14 orang $(50 \%)$. 
Tabel 1

Distribusi Sampel Berdasarkan Karakteristik

\begin{tabular}{lcc}
\hline $\begin{array}{l}\text { KARAKTERISTIK } \\
\text { SAMPEL }\end{array}$ & $\mathbf{n}^{\mathbf{1}}$ & $\mathbf{\%}$ \\
\hline Jenis Kelamin, Perempuan & 18 & 64,3 \\
\hline Usia, 40-67 & 22 & 78,6 \\
\hline Pekerjaan, IRT & 10 & 35,7 \\
\hline Pendidikan, Tamat SMA & 12 & 42,9 \\
\hline Asupan Natrium, Lebih & 16 & 57,1 \\
\hline Status Gizi, Normal & 15 & 53,4 \\
\hline $\begin{array}{l}\text { Tingkat Hipertensi, } \\
\text { Hipertensi Ringan dan } \\
\text { Sedang }\end{array}$ & 14 & 50 \\
\hline
\end{tabular}

\section{Hubungan Asupan Natrium Terhadap Tingkat Hipertensi}

Sampel dengan asupan natrium baik cenderung mengalami hipertensi ringan sebanyak 10 orang $(83,3 \%)$ sedangkan sampel dengan asupan natrium lebih cenderung mengalami hipertensi sedang sebanyak 12 orang $(75 \%)$. Berdasarkan hasil uji statistic yang diperoleh nilai $p=0,003$ yang lebih kecil dari nilai $\alpha(0,05)$ yang berarti ada hubungan antara asupan natrium dengan tingkat hiprertensi.

Tabel 2

Distribusi Sampel Berdasarkan Hubungan Asupan Natrium Terhadap Tingkat Hipertensi di RSUD Kota Makassar

\begin{tabular}{|c|c|c|c|c|c|c|c|}
\hline \multirow{3}{*}{ Asupan Natrium } & \multicolumn{4}{|c|}{ Tingkat Hipertensi } & & & \multirow{3}{*}{$p$} \\
\hline & \multicolumn{2}{|c|}{$\begin{array}{l}\text { Hipertensi } \\
\text { Ringan }\end{array}$} & \multicolumn{2}{|c|}{$\begin{array}{l}\text { Hipertensi } \\
\text { Sedang }\end{array}$} & \multicolumn{2}{|c|}{ Total } & \\
\hline & $\mathrm{n}$ & $\%$ & $\mathrm{n}$ & $\%$ & $\mathrm{n}$ & $\%$ & \\
\hline Baik & 10 & 83,3 & 2 & 16,6 & 12 & 42,9 & \\
\hline Lebih & 4 & 25 & 12 & 75 & 16 & 57,1 & 0,003 \\
\hline TOTAL & 14 & 50 & 14 & 50 & 28 & 100 & \\
\hline
\end{tabular}

$\mathrm{n}^{1}=\mathbf{2 8}$

\section{Hubungan Status Gizi Terhadap Tingkat Hipertensi}

Sampel yang status gizi normal dengan cenderung mengalami hipertensi ringan sebanyak 12 orang $(80 \%)$ sedangkan sampel dengan status Overweight dan Obesitas cenderung mengalami hipertensi sedang sebanyak 11 orang $(84,6 \% \%)$. Berdasarkan hasil uji statistic yang diperoleh nilai $p=0,001$ yang lebih kecil dari nilai $\alpha(0,05)$ yang berarti ada hubungan antara status gizi dengan tingkat hiprertensi. 
Tabel 3

Distribusi Sampel Berdasarkan Hubungan Status Gizi Terhadap Tingkat Hipertensi di RSUD Kota Makassar

\begin{tabular}{lcccccccc}
\hline \multirow{2}{*}{ Status Gizi } & \multicolumn{4}{c}{ Tingkat Hipertensi } & \multicolumn{2}{c}{ Total } & $p$ \\
\cline { 2 - 7 } & \multicolumn{2}{c}{$\begin{array}{c}\text { Hipertensi } \\
\text { Ringan }\end{array}$} & \multicolumn{2}{c}{$\begin{array}{c}\text { Hipertensi } \\
\text { Sedang }\end{array}$} & & & \\
\cline { 2 - 8 } & $\mathrm{n}$ & $\%$ & $\mathrm{n}$ & $\%$ & $\mathrm{n}$ & $\%$ & \\
\hline Normal & 12 & 80 & 3 & 20 & 15 & 53,6 & \\
\hline Overweight dan Obesitas & 2 & 15,3 & 11 & 84,6 & 13 & 46,4 & 0,001 \\
\hline Total & 14 & 50 & 14 & 50 & 28 & 100 & \\
\hline
\end{tabular}

\section{PEMBAHASAN}

Berdasarkan hasil penelitian yang dilakukan di Rumah Sakit Umum Daerah (RSUD Kota Makassar) menunjukkan bahwa sampel dengan asupan natrium baik cenderung mengalami hipertensi ringan sebanyak 10 orang $(83,3 \%)$ sedangkan sampel dengan asupan natrium lebih cenderung mengalami hipertensi sedang sebanyak 12 orang $(75 \%)$. Berdasarkan hasil uji statistic yang diperoleh nilai $p=0,003$ yang lebih kecil dari nilai $\alpha(0,05)$ yang berarti ada hubungan antara asupan natrium dengan tingkat hiprertensi.

Penelitian ini sejalan dengan penelitian yang dilakukan Widyaningrum (2014) dengan sampel lansia di Kelurahan Makamhaji Kecamatan Kartasura yang juga menyatakan bahwa ada hubungan yang signifikan antara asupan natrium dan tekanan darah dengan nilai $p=0,006$ $(<0,05)$. Natrium berhubungan dengan kejadian tekanan darah tinggi karena konsumsi garam yang tinggi dapat mengecilkan diameter dari arteri, sehingga jantung harus memompa lebih keras untuk mendorong volume darah yang semakin sempit dan akan menyebabkan tekanan darah meningkat. Hal yang sebaliknya juga akan terjadi ketika asupan natrium berkurang maka begitu pula volume darah dan tekanan darah pada beberapa individu.

Pengaruh asupan natrium terhadap tingkat hipertensi terjadi melalui peningkatan volume plasma dan tekanan darah. Masyarakat yang mengonsumsi garam dalam jumlah kecil terbukti memiliki riwayat hipertensi yang lebih rendah. Konsumsi natrium yang berlebih menyebabkan komposisi natrium dalam cairan di dalam cairan ekstraseluler meningkat. Untuk menormalkan kembali, cairan intraseluler harus ditarik keluar sehingga volume cairan ekstraseluler meningkat. Meningkatnya cairan ekstraseluler tersebut menyebabkan meningkatnya volume darah naik, sehingga berdampak pada timbulnya hipertensi (Atun 2014).

Berdasarkan hasil penelitian yang dilakukan di Rumah Sakit Umum Daerah (RSUD) Kota Makassar menunjukkan bahwa sampel yang status gizi normal dengan cenderung mengalami hipertensi ringan sebanyak 12 orang (80\%) sedangkan sampel dengan status Overweight dan Obesitas cenderung mengalami hipertensi sedang sebanyak 11 orang $(84,6 \% \%)$. Berdasarkan hasil uji statistic yang diperoleh nilai $p=0,001$ yang lebih kecil dari nilai $\alpha(0,05)$ yang berarti ada hubungan antara status gizi dengan tingkat hiprertensi.

Penelitian ini sejalan dengan penelitian yang dilakukan Manampiring 2008 dengan sampel penduduk usia 45 tahun ke atas di Kelurahan Pakowa Kecamatan Wanea Kota Manado yang juga menyatakan bahwa ada hubungan yang 
signifikan antara status gizi dengan tingkat hipertensi dengan nilai $\mathrm{P}=0,000(<0,05)$.

Resiko relatif untuk menderita hipertensi pada orang gemuk 5 kali lebih tinggi dibandingkan dengan orang yang berat badannya normal, selain itu Indeks Massa Tubuh (IMT) berkorelasi langsung dengan tekanan darah terutama tekanan darah sistolik. Dari sekian banyak penelitian telah membuktikan adanya hubungan antara status gizi dengan kejadian hipertensi pada lansia dan diduga peningkatan berat badan memainkan peranan penting pada mekanisme timbulnya hipertensi pada lansia, gizi lebih juga erat kaitannya dengan kegemaran mengkonsumsi makanan yang mengandung tinggi lemak.

Makin besar massa tubuh, makin banyak darah yang dibutuhkan untuk memasok oksigen dan makanan ke jaringan tubuh. Ini berarti volume darah yang beredar melalui pembuluh darah menjadi meningkat sehingga memberi tekanan lebih besar pada dinding arteri.

\section{KESIMPULAN}

1. Terdapat hubungan yang bermakna antara asupan natrium dan tingkat hipertensi pada pasien hipertensi rawat jalan di RSUD Kota Makassar.

2. Terdapat hubungan yang bermakna antara status gizi dan tingkat hipertensi pada pasien hipertensi rawat jalan di RSUD Kota Makassar.

\section{SARAN}

1. Bagi pasien hipertensi hendaknya memeriksa tekanan darah secara teratur dan sebaiknya pasien hipertensi melaksanakan diet rendah natrium agar tidak terjadi komplikasi penyakit lain lebih lanjut.

2. Bagi instalasi Gizi sebaiknya memberikan konsultasi lebih lanjut tentang diet rendah garam, sebab sebagian besar dari pasien hipertensi rawat jalan yang menjadi respoden tidak mengetahui tentang batasan konsumsi garam dan makanan sumber natrium yang tinggi lainnya.

3. Dilakukan perbaikan status gizi khususnya bagi penderita status gizi lebih dan obesitas untuk menurunkan resiko mengalami hipertensi. Disarankan untuk status gizi normal agar mempertahankan kondisi status gizi sebaik mungkin sehingga tidak berubah ke arah status gizi lebih maupun obesitas.

\section{DAFTAR PUSTAKA}

Almatsier S, 2009. Prinsip Dasar Ilmu Gizi. Jakarta; PT Gramedia Pustaka Utama.

Almatsier S, 2010. Penuntun Diet, Edisi Baru. Jakarta; Kompas Gramedia.

Amrullah A, 2010. Hipertensi. http://blogkesmas.blogspot.co.id/201 0/11/definisi-etiologi-danmekanisme.html .

Anggara F. H. D, 2013. Faktor-Faktor Yang Berhubungan Dengan Tekanan Darah. Prodi S1 Kesehatan Masyarakat, Stikes MH. Thamrin.

Annisah C, dkk., 2011. Gambaran Pola Makan Pada Penderita Hipertensi Yang Menjalani Rawat Inap Di Irna $F$ RSUD Syarifah Ambani Rato Ebu Kabupaten Bangkalan Madura. Prodi DIII Keperawatan, STIKES Yarsi Surabaya.

Atun L, dkk. 2014. Asupan Sumber Natrium, Rasio Kalium Natrium, Aktivitas Fisik, Dan Tekanan Darah Pada Pasien, MGMI. Volume 6.

Ilkafah, 2016. Perbedaan Penurunan Tekanan Darah Lansia Dengan Obat Anti Hipertensi Dan Terapi Rendam Air Hangat Di Wilayah Puskesmas Antara Tamalanrea Makassar. Fakultas Kedokteran, Universitas Hasanuddin. 
Kautsar.F, Aminuddin Syam, Abdul Salam, 2013. Hubungan Status Gizi, Asupan Natrium Dan Kalium Dengan Tekanan Darah Pada Mahasiswa Universitas Hasanuddin Angkatan 2013. Prodi ilmu gizi FKM, Universitas Hasanuddin.

Manampiring A. E, 2008. Hubungan Status Gizi Dan Tekanan Darah Pada Penduduk Usia 45 Tahun Ke Atas Di Kelurahan Pakowa Kecamatan Wanea Kota Manado. Laporan Penelitian. Fakultas Kedokteran Universitas Sam Ratulangi Manado.

Mayasari, M., 2008. Natrium, Kalium, dan Hipertensi. Fakultas Kedokteran Universitas Gadjah Mada. Available from: http://dietsehat.wordpress.com/.

Mustamin, 2010. Asupan Natrium, Status Gizi Dan Tekanan Darah Usia Lanjut. Media Gizi Pangan, Volume IX, Edisi 1.

(diakses, 15 Desember 2015)

Pusparani.ID, 2016. Gambaran Gaya Hidup Pada Penderita Hipertensi. Fakultas Kedokteran, UIN Syarif Hidayatullah Jakarta.

Wardlaw, G.M. et al, 2004. Perspectives in Nutrition. Sixth Edition. McGraw Hill, 383-386.

Widyaningrum A.T. 2014. Hubungan asupan natrium, kalium, magnesium, dan status gizi dengan tekanan darah pada lansia di kelurahan makamhaji kecamatan kartasura. Skripsi. Fakultas Ilmu Kesehatan Universitas Muhammadiyah Surakarta.

Yeni y. dkk 2010. Faktor-Faktor Yang Berhubungan Dengan Kejadian Hipertensi Pada Wanita Usia Subur Di Puskesmas Umbulharjo I Yogyakarta. Kesmas Volume 4. 